\title{
Família, pobreza e acesso a programas de transferência de renda nas regiões metropolitanas brasileiras*
}

\author{
Lilia Montali ${ }^{* *}$ \\ Marcelo Tavares ${ }^{* * *}$
}

\begin{abstract}
O objetivo do artigo é evidenciar nas regiões metropolitanas brasileiras os arranjos familiares mais vulneráveis ao empobrecimento e investigar o acesso destes aos programas de transferência de renda, bem como alguns efeitos desses programas sobre a renda das famílias. Os arranjos domiciliares mais vulneráveis ao empobrecimento são assim identificados por possuírem os mais baixos rendimentos familiares per capita e concentração nos decis inferiores de renda. Apresentam estruturação e composições distintas, bem como vivenciam diferentes momentos do ciclo de vida familiar, mas são os mais fragilizados diante da mudança no padrão de emprego por apresentarem composição familiar desfavorável para a inserção de seus componentes no mercado de trabalho. Nas regiões metropolitanas brasileiras, o empobrecimento dos domicílios ocorrido nos anos 90 e início dos 2000 reflete a queda dos rendimentos do trabalho decorrente da precarização do mercado sob a reestruturação produtiva e o baixo crescimento econômico até 2004. Até 2006, sob a recuperação econômica, tais rendimentos não retornaram aos níveis da metade dos anos 90 . Entre as políticas de combate à pobreza emergem aquelas de transferência de renda, que, no início dos anos 2000, apresentavam abrangência incipiente. Intensificam-se no decorrer da década, possibilitando aumento do acesso dos domicílios com rendimentos mais baixos. Na análise comparativa entre os dados da PNAD 2004 e 2006, procura-se identificar o acesso aos programas de transferência de renda pelos domicílios caracterizados por diferentes tipos de arranjos familiares, considerando sua estruturação e momento do ciclo de vida familiar. Um dos impactos a serem investigados dentre estes é a redução dos domicílios sem rendimento. Investigase também a diminuição da desigualdade de renda entre os arranjos familiares mais vulneráveis e os demais tipos, mesmo que ainda permaneçam as diferenças de rendimento per capita.
\end{abstract}

Palavras-chave: Família-trabalho. Empobrecimento. Programas de transferência de renda.

\section{Introdução}

Muitos estudos analisaram o impacto dos programas de transferência de renda na redução da desigualdade de renda no país, tendo por referência os resultados da PNAD 2004. Entre as diversas interpretações, houve certo consenso ao se atribuir

\footnotetext{
* Trabalho apresentado no XVI Encontro Nacional de Estudos Populacionais, Abep, realizado em Caxambu, MG, Brasil, de 29 de setembro a 03 de outubro de 2008. Apresenta resultados de projeto de pesquisa desenvolvido com apoio do CNPq, junto ao Nepp/Unicamp - Universidade Estadual de Campinas.

${ }^{* *}$ Pesquisadora do Núcleo de Estudos de Políticas Públicas - Nepp-Unicamp. Pesquisadora do CNPq.

${ }^{* * *}$ Estatístico do Núcleo de Estudos de Políticas Públicas - Nepp-Unicamp. Apoio Técnico - CNPq.
} 
a um conjunto de fatores a participação na redução da desigualdade observada, entre os quais se destacaram a ampliação dos programas sociais de transferência de renda, a recuperação do salário mínimo e uma pequena retomada do emprego assalariado (DEDECCA, 2006; BARROS et al. 2006). Entretanto, o atual debate sobre a redução das desigualdades de renda evidencia o peso das transferências de renda (SOARES at. al., 2006; SCHWARTZMAN, 2006), o que justifica a busca de maior conhecimento dos impactos destas sobre as famílias beneficiárias.

A proposta deste artigo é identificar o acesso e alguns efeitos da recuperação econômica e dos programas de transferência de renda sobre os arranjos domiciliares que apresentam maiores possibilidades de serem pobres, caracterizados pelas médias de renda domiciliar per capita menores do que a média regional e pela maior concentração nos decis inferiores de renda. Estes domicílios apresentam estruturação e composições distintas, bem como vivenciam diferentes momentos do ciclo de vida familiar, mas são os mais fragilizados diante da mudança no padrão de emprego por apresentarem composição familiar desfavorável para a inserção de seus componentes no mercado de trabalho.

Procura-se identificar o acesso aos programas de transferência de renda pelos domicílios caracterizados por diferentes tipos de arranjos familiares, considerando sua estruturação e momento do ciclo de vida familiar. Outra questão a ser investigada é o efeito das transferências de renda sobre a renda das famílias, buscando-se indicações de redução da desigualdade a partir das famílias.

Visando tratar tais temas, este artigo é composto por três itens e pelas considerações finais. $O$ primeiro refere-se ao empobrecimento nas regiões metropolitanas brasileiras sob o contexto da precarização do trabalho. O segundo caracteriza os arranjos domiciliares mais vulneráveis ao empobrecimento e o terceiro aborda o acesso aos programas de transferência de renda e alguns efeitos sobre os domicílios considerados segundo tipos de arranjos domiciliares.

\section{O empobrecimento nas regiões metropolitanas brasileiras e os impactos sobre as famílias}

Estudo longitudinal sobre a pobreza no Brasil (trajetória 1970-1999) aponta redução da proporção dos contingentes mais pobres na área rural - relacionada aos processos de urbanização e de industrialização -, um comportamento menos favorável nas áreas urbanas não metropolitanas, bem como a tendência de metropolização da pobreza (ROCHA, 2003). Nos anos 90, após o período de queda da proporção de pobres para todas as áreas de residência (1994-1995), como decorrência temporária do sucesso do plano de estabilização de 1994 (Plano Real), sucedem-se a continuidade da meIhora dos indicadores para as áreas rurais e a piora para as regiões metropolitanas (ROCHA, 2006). Segundo a autora, a queda das proporções de pobres e indigentes nas áreas rurais e a redução da população rural tornaram a pobreza e a indigência no Brasil crescentemente fenômenos urbanos e metropolitanos.

Entre 1995 e 2003, houve tendência de crescimento da proporção de pobres no conjunto das regiões metropolitanas brasileiras mais intensa do que para as áreas rurais e as urbanas (ROCHA, 2006). Além disso, a queda na proporção de pobres ocorrida em 2004 em todas as áreas de residência foi comparativamente mais tênue para as nove regiões metropolitanas brasileiras, que incluem as capitais estaduais para as quais a PNAD-IBGE realiza levantamentos periódicos (ROCHA, 2006).

$O$ estudo de Rocha mostra ainda que há diferenças entre as regiões metropolitanas, com comportamento desfavorável mais acentuado para a de São Paulo, que apresentou evolução adversa da pobreza entre 2003 e 2004. Dessa maneira, a análise do estrato metropolitano - uma média dos resultados das regiões metropolitanas brasileiras - evidencia que este é afetado pelo maior peso relativo da região metropolitana de São Paulo. A autora elenca quatro fatores explicativos desse resultado: fraca criação de postos de trabalho; evolução desfavorável do rendimento do trabalho; 
aumento relativamente forte do custo de vida dos pobres; e menor impacto positivo dos programas de transferência de renda com valores fixados com base em parâmetros nacionais (ROCHA, 2006).

Os dados da PNAD 2006 indicam, segundo Rocha, queda na proporção de pobres na população brasileira, que passa a ser de $26,9 \%$, e reafirmam as tendências de concentração da pobreza nas áreas urbanas e metropolitanas. Para as regiões metropolitanas, em movimento contrário ao verificado na população do país, ocorreu crescimento da proporção de pobres: de $35,5 \%$ para $36,3 \%$ da população destas áreas, entre 2005 e 2006 (Folha de S. Paulo, 19 de setembro de 2007).

Deve-se considerar que o processo de reestruturação produtiva afetou com mais intensidade as áreas metropolitanas brasileiras em detrimento das urbanas não metropolitanas e das rurais, e vem atuando de forma diferenciada entre as regiões metropolitanas quanto à organização das atividades econômicas. A reestruturação produtiva intensificada a partir de 1990 elevou o patamar de desemprego e a precarização das relações de trabalho, com redução do assalariamento regulamentado e aumento de vinculações menos protegidas, como trabalho autônomo e assalariamento sem carteira assinada, bem como instauração de novas formas de contratação.

Tais alterações no mercado de trabalho provocaram, desde o início dos anos 90, progressiva queda dos rendimentos dos ocupados. Análise do mercado de trabalho nas regiões metropolitanas mostra redução no rendimento médio real dos ocupados, entre 1998 e 2005, da ordem de $4,1 \%$ ao ano, equivalendo a uma perda acumulada de $25,6 \%$ no período (FUNDAÇÃO SEADE; DIEESE, 2007). ${ }^{1}$ As perdas mais intensas ocorreram nas regiões metropolitanas de São Paulo e de Recife, da ordem de 5,0\% e $4,9 \%$ ao ano, respectivamente. A queda do rendimento dos ocupados é apontada por diversos estudos, tais como os de Mendonça e Hoffmann (2006), Fundação Seade (2007) e Rocha (2006).

Apesar da retomada do crescimento do emprego a partir de 2004 e da elevação do rendimento dos ocupados, dados da Fundação Seade para essas mesmas regiões metropolitanas indicam recuperação bastante modesta do crescimento do rendimento real dos ocupados. Entre 2006 e 2007 , o emprego cresceu $3,5 \%$ nas regiões metropolitanas, ao passo que o rendimento médio dos ocupados elevou-se em 1,3\%. Ao retomar a análise a partir de 1998, o estudo mostra, para o período 1998 a 2007, a permanência da queda do rendimento médio real dos ocupados $(-22,6 \%)$, concomitante ao crescimento do emprego de $26,3 \%$. Essas tendências são interpretadas como indicativas de aumento do emprego com remunerações baixas, inclusive para os assalariados, pois, se para estes é mais acentuado o crescimento do emprego $(34,6 \%)$, permanece elevada a queda do rendimento (-19,8\%) para o período (FUNDAÇÃO SEADE; DIEESE, 2007). ${ }^{2}$

O empobrecimento dos domicílios analisado nos anos 90 e início dos 2000 na Região Metropolitana de São Paulo, expresso pela queda da renda familiar per capita (MONTALI, 2006), reflete a queda dos rendimentos do trabalho resultante da precarização do trabalho e do desemprego recorrente, sob a reestruturação produtiva e o baixo crescimento econômico até 2004 . Constatou-se ainda, enquanto uma forma de enfrentamento do desemprego e da mudança do padrão do emprego - que afetou mais fortemente os provedores masculinos e filhos jovens e possibilitou aumento da participação feminina -, a articulação de rearranjos familiares de inserção no mercado de trabalho, com maior participação da cônjuge e da chefe feminina em atividades remuneradas e na provisão familiar. No caso da Região Metropolitana de São Paulo, estudo longitudinal do final da década 80 até a

\footnotetext{
1 O agregado metropolitano do Sistema PED apresenta algumas distinções em relação ao do IBGE, pois abrange seis regiões metropolitanas (São Paulo, Porto Alegre, Distrito Federal, Belo Horizonte, Salvador e Recife).

2 Informações disponíveis em: <http://www.seade.gov.br>, PED - Regiões Metropolitanas - tabelas 10 e 11. Acesso em: 02/04/2008.
} 
primeira metade dos anos 2000 evidenciou que esses rearranjos familiares de inserção no mercado de trabalho articulados a partir dos anos 90 atenuaram o empobrecimento, porém não impediram a queda da renda domiciliar (MONTALI, 2004a; 2006).

Este estudo sobre a Região Metropolitana de São Paulo mostra, ainda, que as atuais tendências de precarização do trabalho e de aumento do desemprego afetam diferenciadamente os arranjos familiares de inserção no mercado, articulados de maneiras distintas nos momentos do ciclo de vida familiar, evidenciando maior fragilização para determinados segmentos sociais nas formas encontradas para garantir a sobrevivência (MONTALI, 2004a e 2006). Coincidentemente com estes achados, Schwartzman (2006), utilizando categorias aproximadas, indica os mesmos tipos de família como os mais freqüentes nos decis inferiores de renda familiar per capita na análise sobre as famílias brasileiras em 2004. Um dos objetivos deste estudo, como mencionado, é identificar características dos arranjos domiciliares mais suscetíveis ao empobrecimento.

Estudo recém divulgado indica tendência de redução da pobreza (famílias com renda per capita de até $1 / 2$ salário) nas regiões metropolitanas, a partir de 2003 até 2007, com projeção de queda para 2008 (IPEA, 2008). De forma coincidente com o apresentado nesse item, embora com metodologia distinta, o estudo do Ipea mostra que, entre 1995 e 2003, ocorreu elevação na proporção de pobres em relação ao total da população das regiões metropolitanas: permaneceu pouco acima de 25\% entre 1995 e 1998; voltou a crescer a partir de 1999, quando passou de $28 \%$ nesse ano para $32 \%$ em 2003. Essa proporção diminuiu progressivamente entre 2004 e 2006, passando de $30 \%$ para $23,5 \%$. Deve-se ressaltar que o Ipea adota metodologia distinta daquela utilizada por Rocha para a definição de pobreza, o que explica algumas diferenças entre os números destes estudos. ${ }^{3}$

\section{Os arranjos domiciliares mais vulneráveis ao empobrecimento nas regiões metropolitanas brasileiras}

A composição dos arranjos familiares e o ciclo vital das famílias são referências fundamentais na presente análise dos grupos de famílias mais vulneráveis ao empobrecimento nos contextos regionais diferenciados. Não se ignora, no entanto, a importância de outros fatores, tais como o acesso aos ativos sociais e econômicos e a ocupações de qualidade.

Os arranjos familiares que apresentam maiores fragilidades para garantir a sobrevivência, sendo mais vulneráveis ao empobrecimento, apresentam características semelhantes nas regiões metropolitanas brasileiras. Quanto à composição, são assim identificados os arranjos domiciliares nucleados pelo casal com idades de até 34 anos com filhos e/ou parentes, aqueles em que o casal tem idades entre 34 e 49 anos, também com a presença de filhos e/ou parentes, e as famílias chefiadas por mulher com a presença de filhos e/ou parentes. Estes arranjos domiciliares apresentam composições distintas, vivenciam momentos diferentes do ciclo de vida familiar, mas têm em comum composição desfavorável para a inserção de seus componentes no mercado de trabalho ou em atividades de geração de renda, por abrigarem crianças e adolescentes ou idosos, expressa nas taxas de geração de renda comparativamente mais baixas. Apresentam rendimentos médios familiares per capita inferiores aos demais arranjos domiciliares e abaixo da média regional (Tabela 1), possuem as mais elevadas concentrações entre os decis inferiores de renda familiar per capita (Tabela 2) e registram menores taxas de geração de renda (Tabela 3).

As características de composição destes domicílios nas áreas metropolitanas brasileiras e o momento do ciclo vital dos arranjos familiares mais vulneráveis ao empobrecimento são os seguintes: no primeiro

\footnotetext{
3 O Ipea considera pobres as pessoas com rendimento per capita igual ou inferior a meio salário mínimo. Sonia Rocha (2003 e 2006) define pobreza tomando como referência linhas de pobreza baseadas em necessidades básicas e o custo de vida diferenciado por áreas urbanas e rurais, segundo regiões brasileiras.
} 
grupo - identificado pelo casal com idades de até 34 anos com filhos e parentes -, quase a totalidade dos filhos tem menos de 14 anos, remetendo à etapa inicial do ciclo de vida familiar, quando se dá a maior parte dos nascimentos; no segundo arranjo domiciliar referido - casal com idade entre 34 e 49 anos, correspondendo à etapa de consolidação -, com presença de filhos e/ou parentes, os filhos dividem-se entre menores e maiores de 14 anos; nos arranjos domiciliares chefiados por mulher com a presença de filhos e/ou parentes, cerca de um terço dos filhos tem menos de 14 anos, um terço apresenta idades entre 14 e 24 e um terço está acima de 24 anos. ${ }^{4}$ A despeito das especificidades de cada arranjo domiciliar, todos incluem crianças e adolescentes e os dois últimos contam com jovens entre seus componentes.

Os dois primeiros tipos de arranjos domiciliares demandam investimentos e atenção em educação e saúde e a manutenção da família recai sobre os componentes adultos, ou seja, o casal, pois os parentes constituem menos de $10 \%$ dos componentes, sendo cerca de metade destes menores de 18 anos. No caso das chefes femininas sem cônjuge e com presença de filhos, há especificidades na composição familiar relacionadas aos momentos do ciclo de vida familiar a que correspondem. Há a presença de idosos, porém é recorrente a presença de filhos crianças e adolescentes (22\% dos componentes), bem como a de parentes menores de 18 anos (11\% dos componentes), sugerindo, em muitos casos, família extensa. A presença de jovens entre 18 e 24 anos (10\% dos componentes no arranjo domiciliar chefe feminina sem cônjuge) constitui, especialmente entre os grupos de menor escolaridade, um agravante para as condições de sobrevivência desses domicílios, considerando-se a crise do emprego jovem verificada a partir da década de 90 .

Arriagada (2007, p. 237), em estudo sobre as famílias latino-americanas em zonas urbanas, indica, de forma semelhante, maior incidência da pobreza nos lares monoparentais com chefia feminina e entre as famílias nucleares com filhos nas etapas do ciclo de vida familiar relacionadas à expansão $e$ consolidação. Nesse estudo, a autora relaciona estruturas familiares e etapas do ciclo de vida familiar com a incidência da pobreza e de bem-estar.

A maior vulnerabilidade à pobreza é evidenciada no tipo de arranjo domiciliar caracterizado pelo casal mais jovem com filhos, cujo rendimento familiar per capita médio, em 2004, correspondia a cerca de $59 \%$ da média do rendimento familiar per capita do respectivo agrupamento de região metropolitana segundo grandes regiões brasileiras. Esse percentual é levemente maior nas regiões metropolitanas do Norte (64\%) e do Nordeste (61\%), que, comparativamente, apresentam os menores valores médios per capita regionais (Tabela 1 ).

Observa-se para esse grupo de domicílios, em 2006, aumento da diferença em relação tanto às médias regionais quanto ao total metropolitano, como se pode constatar na Tabela 1. Os domicílios caracterizados por arranjos nucleados pelo casal mais jovem, de até 34 anos, com a presença de filhos passaram a apresentar, em 2006, renda familiar per capita cerca de $57 \%$ da média regional metropolitana. 0 aumento da distância em relação à renda média deve-se ao crescimento da renda per capita média metropolitana mais intenso do que o experimentado pelos domicílios dos casais mais jovens com filhos e/ou parentes. Verificou-se crescimento do rendimento familiar per capita, entre 2004 e 2006, para todos os tipos de arranjos familiares, porém estes e os domicílios nucleados pela chefe feminina sem cônjuge, exatamente os caracterizados como mais vulneráveis ao empobrecimento, apresentaram aumento inferior ao da média regional metropolitana, reproduzindo a desigualdade de renda entre os domicílios.

\footnotetext{
${ }^{4}$ Considerando-se os grupos de idades enquanto aproximação das etapas do ciclo vital das famílias, as chefes femininas sem cônjuge apresentam as seguintes distribuições em 2004 e 2006: até 34 anos 14\% (na etapa de constituição da família); entre 35 e 49 anos (etapa da consolidação), cerca de 31\%; com 50 anos e mais (etapa do envelhecimento), cerca de 55\%. Microdados PNAD, elaboração dos autores.
} 
Os arranjos chefiados por mulher com presença de filhos e parentes constituem o segundo grupo na escala entre os mais vulneráveis à pobreza. Em 2004, o rendimento médio per capita dos domicílios com esse arranjo representava cerca de $81 \%$ daquele referente ao total das regiões metropolitanas, passando para cerca de 78\% em 2006. Repete-se aqui o fato de essa proporção ser mais elevada nas regiões metropolitanas do Norte e do Nordeste, que apresentam valores de rendimentos mais baixos na comparação como os dois outros agrupamentos de regiões.

O terceiro tipo de arranjo domiciliar mais vulnerável ao empobrecimento é caracterizado pelo casal com idades entre 34 e 49 anos com filhos e parentes. Embora se encontrem entre aqueles com rendimento familiar per capita médio mais baixo, esses domicílios ficaram muito próximos da média regional metropolitana em 2004, cerca de

TABELA 1

Rendimento domiciliar per capita médio, segundo tipos de arranjo domiciliar Agrupamento de regiões metropolitanas segundo grandes regióes - 2004-2006

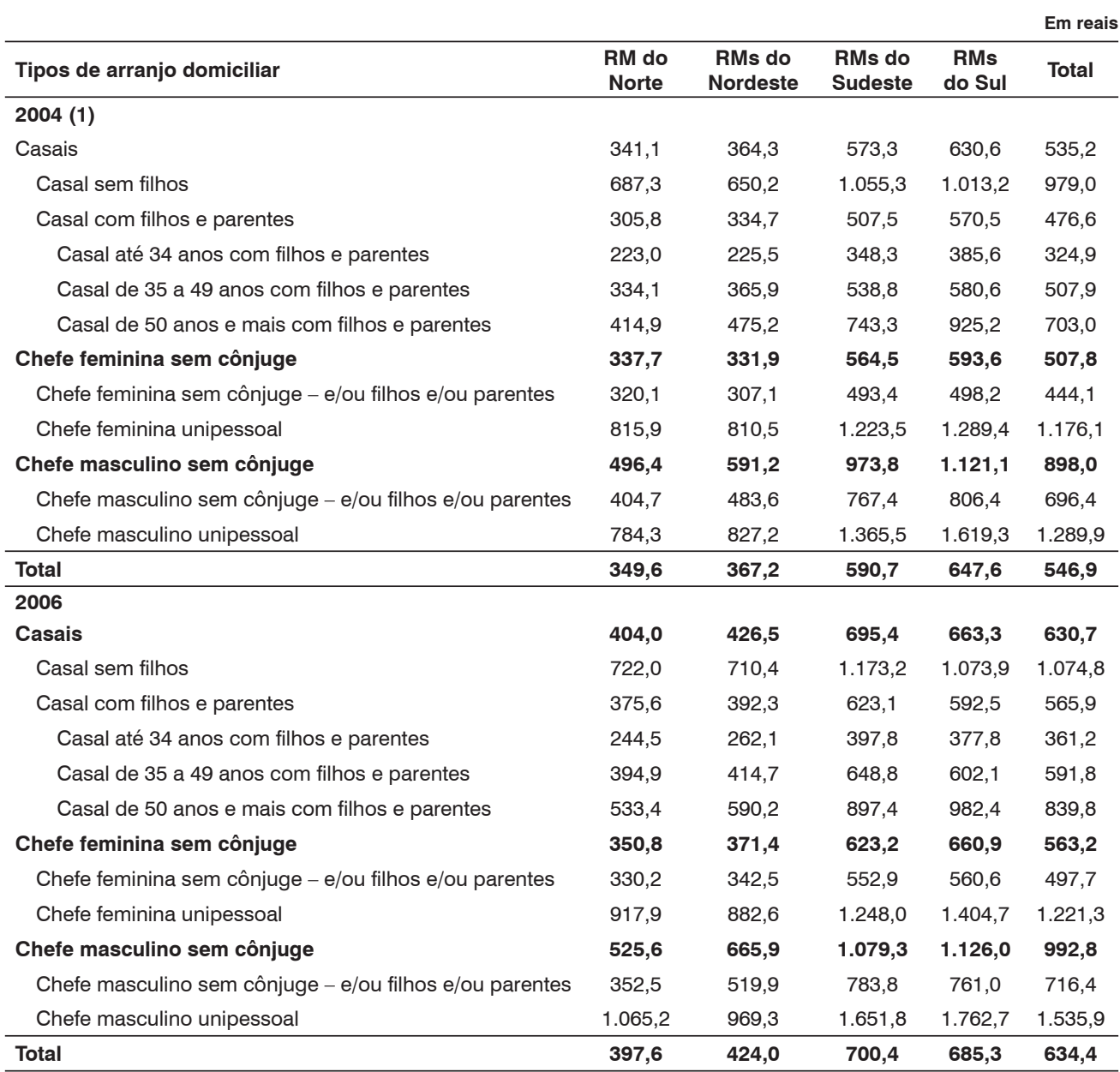

Fonte: IBGE. Pesquisa Nacional por Amostra de Domicílios. Microdados. Elaboração dos autores, Nepp/Unicamp.

(1) Em valores de 2006 (INPC).

Nota: O total inclui outros tipos de arranjos domiciliares (residual).

Região Norte: RM de Belém; Região Nordeste: RMs de Fortaleza Recife e Salvador; Região Sudeste: RMs de Belo Horizonte, Rio de Janeiro e São Paulo; Região Sul: RMs de Curitiba e Porto Alegre. 
$93 \%$, mantendo-se de forma semelhante em 2006.

Diferente do esperado, não ocorre redução da distância entre os rendimentos per capita médios dos arranjos domiciliares e a média regional, como indicativo de uma pequena redução da desigualdade entre os diferentes arranjos em um contexto metropolitano de arrefecimento da queda da renda domiciliar e de expansão dos programas de transferência de renda. No conjunto das regiões metropolitanas brasileiras, houve pequena elevação nas médias per capita de rendimento por tipo de arranjo domiciliar, segundo configurações familiares - nucleadas por casais ou chefes sem cônjuges - associadas aos momentos do ciclo vital. No entanto, a elevação do rendimento familiar per capita é distinta entre os tipos de arranjos domiciliares e menor do que o crescimento regional para dois dos tipos de arranjos entre os identificados como mais vulneráveis ao empobrecimento (casais de até 34 anos e casais de 35 a 49 anos, ambos com filhos e parentes). No caso dos arranjos domiciliares nucleados por chefes femininas sem cônjuge e com filhos, o aumento do rendimento domiciliar per capita é semelhante ao observado para a média regional metropolitana (Tabela $1 \mathrm{e}$ Gráfico 1).

Os arranjos domiciliares identificados como mais vulneráveis ao empobrecimento, além de possuírem os níveis mais baixos de rendimentos familiares per capita, também apresentam maior concentração nos decis inferiores de renda domiciliar. Uma das evidências desse fato é o cotejamento entre as proporções de arranjos domiciliares por tipologia e sua distribuição por decis de renda (Tabela 2). Em conjunto, os três tipos de arranjos domiciliares mais vulneráveis correspondiam, em 2004 e 2006, a cerca de $58 \%$ dos domicílios das regiões metropolitanas brasileiras, no entanto, representavam $71 \%$ dos domicílios abaixo do valor do 5응 decil da distribuição de renda domiciliar per capita metropolitana, que identifica os $50 \%$ mais pobres.

Considerando-se o conjunto dos domicílios metropolitanos nesse período, cerca de $44 \%$ encontravam-se abaixo do 5o decil

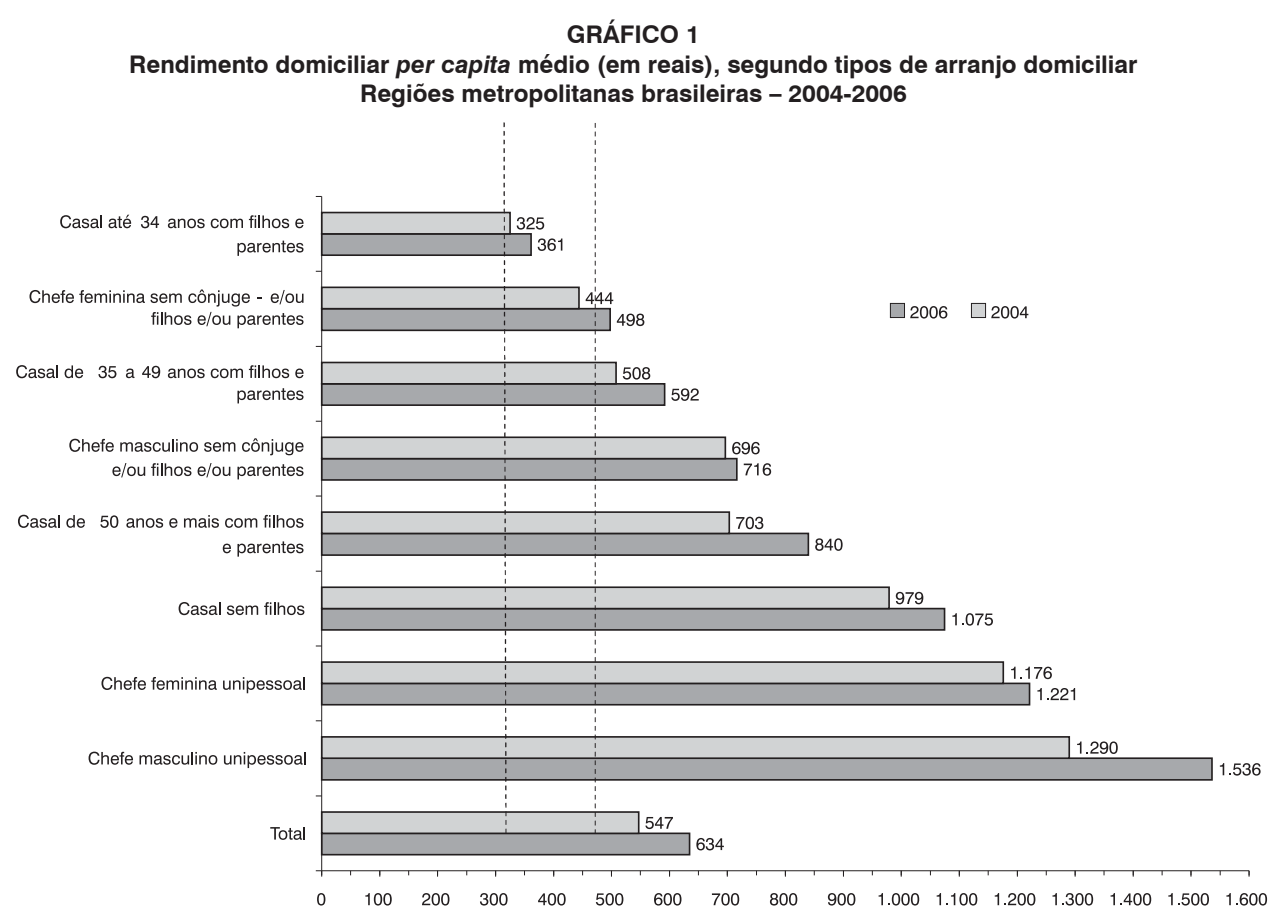

Fonte: IBGE. Pesquisa Nacional por Amostra de Domicílios 2004 e 2006. Processamento próprio. 


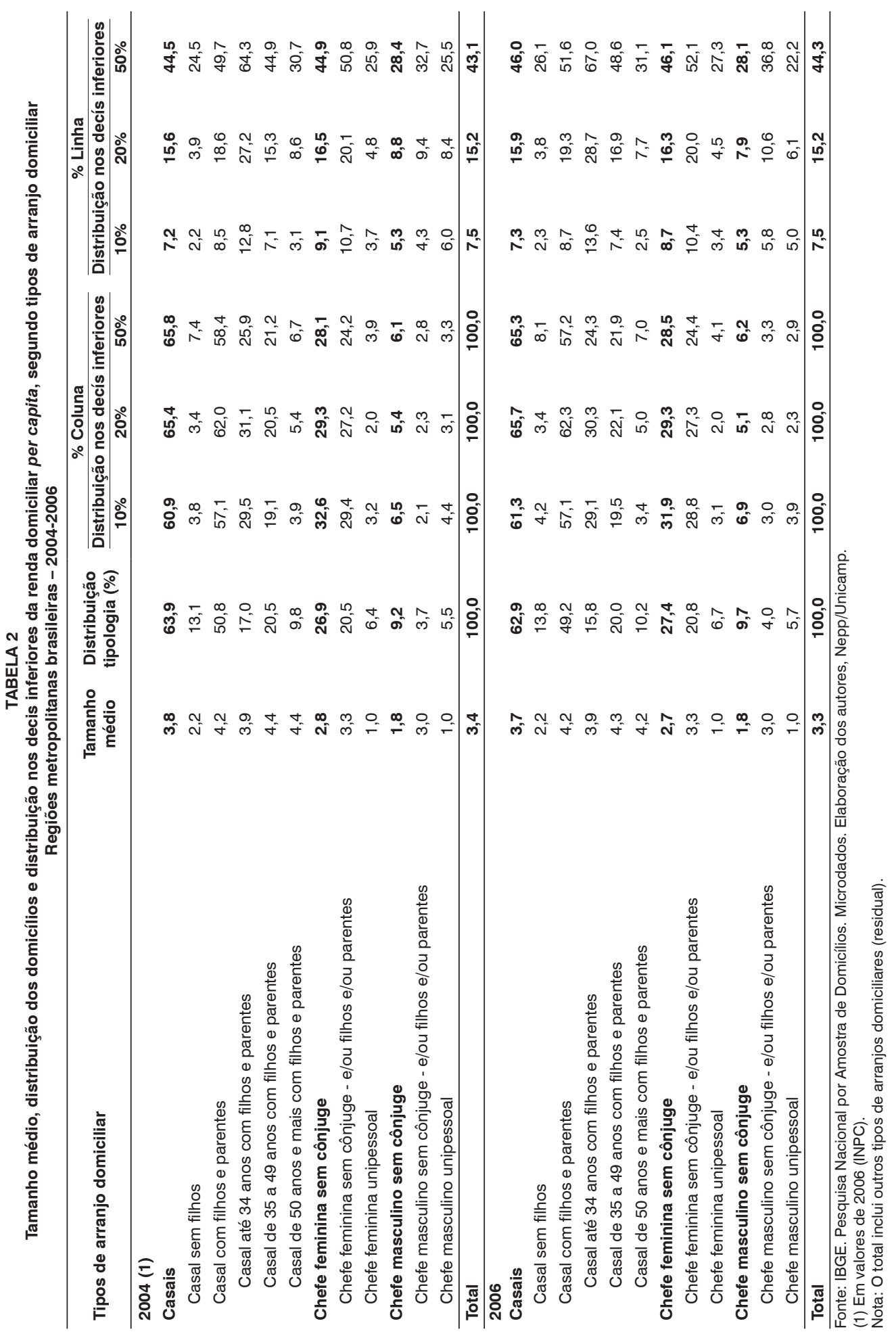


da distribuição de renda domiciliar per capita das regiões metropolitanas brasileiras, ou seja, entre os $50 \%$ mais pobres. Em ambos os anos analisados, as concentrações apresentadas por cada um dos três tipos de arranjos domiciliares mais vulneráveis ao empobrecimento situavam-se acima dessa proporção média. Em 2006, estavam abaixo do valor do 50 decil cerca de $67 \%$ dos domicílios dos casais jovens, de até 34 anos com filhos, $52 \%$ dos domicílios com chefe feminina sem cônjuge e com a presença de filhos e $49 \%$ dos casais entre 35 e 45 anos, com filhos (Tabela 2).
Outra característica dos grupos domiciliares mais vulneráveis ao empobrecimento é apresentarem taxas de geração de renda comparativamente menores do que as dos demais tipos de arranjos domiciliares e de maneira bastante semelhante entre os agrupamentos de regiões metropolitanas brasileiras (Tabela 3). É interessante observar que há uma gradação com menores taxas na RM do Norte, crescendo para as do Nordeste, do Sudeste e as do Sul.

Entre os tipos de arranjo domiciliar mais vulneráveis ao empobrecimento, aqueles dos casais jovens com filhos apresentam a

TABELA 3

Taxa específica de geração de renda, segundo tipos de arranjo domiciliar Agrupamento de regiões metropolitanas segundo grandes regiões - 2004-2006

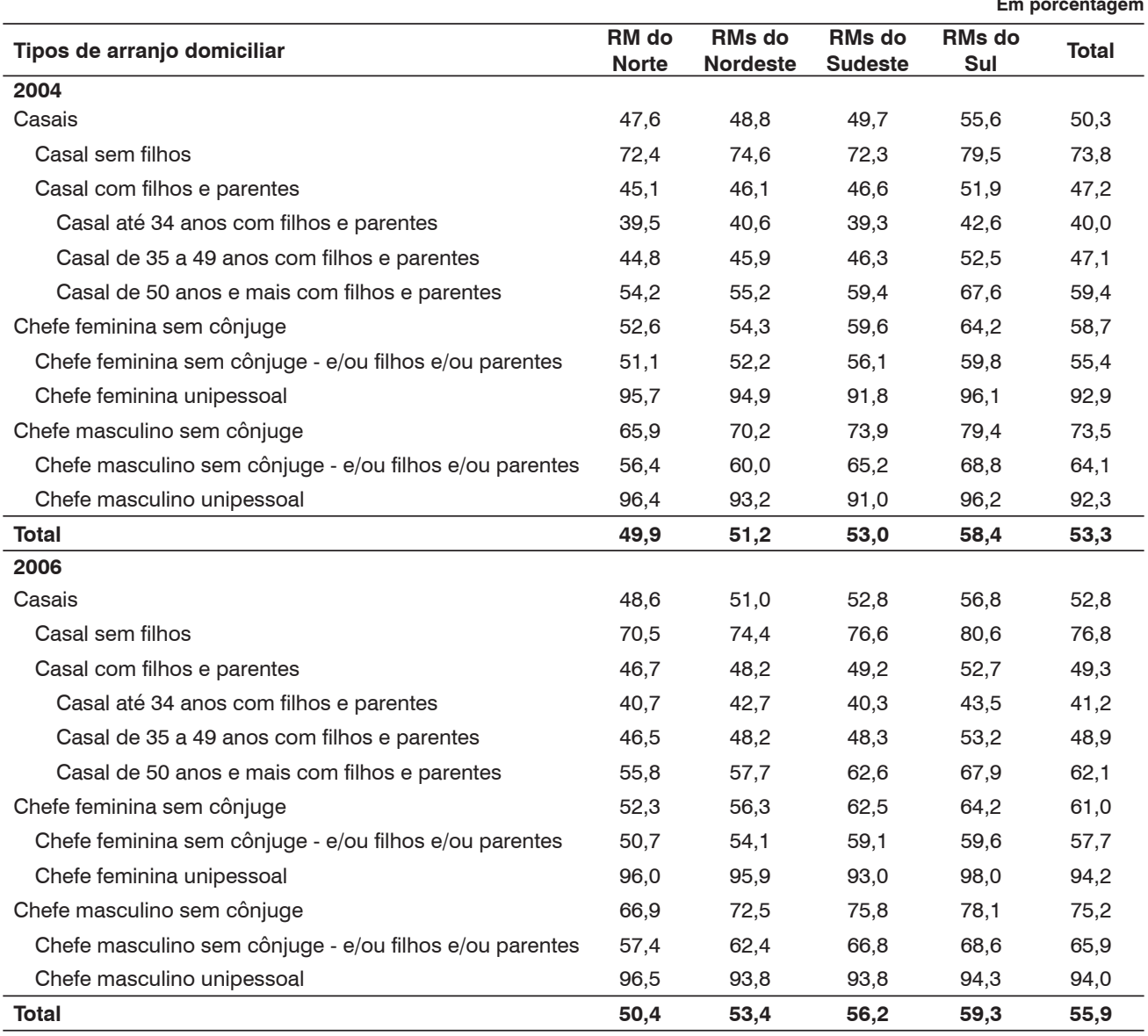

Fonte: IBGE. Pesquisa Nacional por Amostra de Domicílios. Elaboração dos autores, Nepp/Unicamp.

Nota: Excluídos da análise dos domicílios/família os pensionistas, empregados domésticos residentes e parentes dos empregados domésticos. 
menor taxa de geração de renda, nos quais cerca de $40 \%$ dos componentes maiores de dez anos aportavam renda para o grupo domiciliar, em 2004, e 41\%, em 2006; entre os arranjos domiciliares dos casais de 35 a 49 anos com filhos, cerca de $47 \%$ dos componentes geravam renda, em 2004, e $49 \%$, em 2006. Nos domicílios chefiados por mulher com a presença de filhos, essas proporções eram de cerca de $55 \%$ e $58 \%$ nos dois anos, evidenciando o empenho do grupo para a provisão familiar. Nos demais arranjos domiciliares, essa taxa é bastante superior e a taxa de geração de renda para a média das famílias metropolitanas era da ordem de 53\%, em 2004, e de 56\%, em 2006 (Tabela 3).

Ainda que essa diferenciação nas taxas de geração de renda menos elevadas para os domicílios mais vulneráveis ao empobrecimento se mantenha em 2006, observa-se um aumento de 2,6 pontos percentuais nas taxas, considerando-se o total dos domicílios metropolitanos. A elevação da taxa de geração de renda reflete a expansão do emprego, bem como o acesso a programas de transferência de renda e apresenta variações distintas entre os agrupamentos de regiões metropolitanas. Entre os arranjos domiciliares mais vulneráveis ao empobrecimento, aqueles de casais jovens com filhos e de casais de até 34 anos com filhos apresentaram, no período, crescimento da taxa de geração de renda menor do que a média dos domicílios metropolitanos. No caso das famílias com chefia feminina sem a presença de cônjuge, a taxa de geração de renda aproximou-se da média regional e o crescimento verificado entre 2004 e 2006 foi próximo da média metropolitana. Entretanto, a análise da qualidade da ocupação indica, para os domicílios com esse arranjo, proporção mais elevada de ocupações precárias $(51,2 \%$ em 2006), enquanto a média nos domicílios metropolitanos era de 46,8\% (MONTALI, 2008). As características dos componentes desse arranjo domiciliar, apresentadas no primeiro item deste artigo, condicionam suas possibilidades da inserção no mercado de trabalho.

\section{O acesso aos programas de transferência de renda e os arranjos domiciliares}

No decorrer da década de 2000 , entre as políticas de combate à pobreza, ampliouse a cobertura daquelas de transferência de renda. Os programas desta natureza apresentaram abrangência incipiente em 2000, com predominância de programas municipais, que passaram a ser implementados a partir de $1995,{ }^{5}$ além de dois programas federais: o Beneficio de Prestação Continuada (BPC) e o Programa de Erradicação do Trabalho Infantil (PETI), instituídos em 1996. No decorrer dos anos 2000, aumentou a cobertura dos programas de transferência de renda com a ampliação da implementação destes dois programas federais e, a partir de 2001, com a implementação dos programas Bolsa-Escola e Bolsa-Alimentação e, na seqüência, os programas Auxílio-Gás, em 2002, e o Cartão Alimentação, em 2003. A partir de outubro de 2003, com a implementação do Programa Bolsa-Família, que unifica quatro programas de transferência e gradativamente amplia a cobertura, aumentou o acesso a esse tipo de programa de combate à pobreza pelos domicílios com rendimentos mais baixos. ${ }^{6}$

Concomitante à ampliação desse tipo de política de combate à pobreza, assistese à emergência da família como referência nas políticas de transferência de renda no país. A relevância da família como referência para as políticas sociais vem sendo explicitada a partir de 1993, com a instituição da

\footnotetext{
5 Detalhamento dos programas municipais de transferência de renda nesse período pode ser encontrado em Fonseca (2001).

${ }^{6}$ Programas federais de transferência de renda implementados antes de 2000: PETI e BPC (1996). Principais programas de transferência de renda federais implantados na década de 2000: Programa Nacional de Renda Mínima - Bolsa-Escola (abril/2001), vinculado à educação, e Bolsa-Alimentação (setembro/2001), vinculado à saúde -; Programa Auxílio-Gás (janeiro/2002); Programa Nacional de Acesso à Alimentação - Cartão Alimentação (junho/2003). O Programa BolsaFamília unifica estes programas e amplia a cobertura (outubro/2003, regulamentado pelo Decreto n.5.209 de 17 de setembro de 2004).
} 
Loas (Lei Orgânica da Assistência Social), ${ }^{7}$ quando a família passou a ter centralidade para concepção e implementação dos benefícios, serviços, programas e projetos, como um dos princípios da Política Nacional de Assistência Social (BRASIL, MPAS/SAS, 1999, p.66).

A centralidade da família para os programas sociais é reafirmada nas diretrizes da atual gestão federal, através da Política Nacional de Assistência Social. 8 É também explicitada no Programa Bolsa-Família, que se propõe a atingir a totalidade das famílias pobres, diferenciando-se dos programas anteriores, ao eleger a família como unidade do programa, o que significa ter o conjunto dos componentes como público-alvo e não mais cada um isoladamente, propondo a articulação de programas sociais que visam a superação da pobreza, o resgate da cidadania e a inserção social (FONSECA; COHN, 2004).

Tomando como referência os grupos de arranjos domiciliares mais vulneráveis ao empobrecimento, investiga-se aqui o acesso destes aos programas de transferência de renda. Para tanto, utilizou-se um recurso enquanto aproximação, a partir dos microdados da PNAD 2006 - IBGE. A estimativa do acesso dos domicílios metropolitanos a benefícios de transferência de renda foi calculada a partir da variável V1273 (Outros rendimentos recebidos na semana de referência), que inclui o rendimento mensal recebido de programa governamental de transferência de renda e também os juros de aplicações financeiras. Visando estimar os benefícios oriundos das transferências de renda, utilizou-se a referida variável, adotando como critério a exclusão dos domicílios com rendimentos superiores ao 8 으 decil de rendimento familiar per capita, ou seja, o $9^{\circ} \mathrm{e}$ o 10 ㅇ decis, que correspondem a $R \$ 705,28$, em 2004, e a $R \$ 800,00$, em 2006 (em valores de 2006), ${ }^{9}$ tendo por suposto reduzir a interferência de rendimentos oriundos de juros de aplicações financeiras que também estão incluídos na variável utilizada.

Constatou-se ser ainda bastante modesto o acesso dos domicílios das metrópoles brasileiras a programas de transferência de renda. Cerca de $9 \%$ deles tinham acesso a pelo menos um programa dessa natureza por ocasião do levantamento feito pela PNAD-IBGE, em 2004, e pouco mais de $11 \%$, em 2006. Percentual este insuficiente mesmo para atender aos domicílios com rendimento familiar per capita situado nos dois decis inferiores de renda, que perfazem $15,2 \%$ dos domicílios metropolitanos nos dois momentos, conforme indicado no item anterior (Tabela 2). ${ }^{10}$

Para o total dos domicílios brasileiros, 18,3\% receberam em 2006 transferência de renda de programa social do governo (IBGE, 2008, Tabela 1.2.3). Existem diferenças regionais na distribuição dos domicílios brasileiros com acesso a tais programas governamentais e as maiores proporções são encontradas nas regiões Nordeste $(35,9 \%)$ e Norte (24,6\%), seguidas pelo Centro-Oeste (18\%), Sul $(10,4 \%)$ e Sudeste $(10,3 \%)$.

Ainda que insuficiente para as regiões metropolitanas brasileiras, o acesso à transferência de renda de programa social do governo mostra-se bem focalizado, pois cerca de $91 \%$ dos domicílios metropolitanos beneficiários encontravam-se entre os $50 \%$ mais pobres em 2004 e 2006 (Tabela 4). A focalização dos programas sociais de transferência de renda é evidenciada também nas proporções mais elevadas do que a média

\footnotetext{
7 Lei Orgânica da Assistência Social - Lei n. 8.742, de 7 de dezembro de 1993.

8 Política Nacional de Assistência Social. Resolução no 145, de 15 de outubro de 2004 (DOU 28/10/2004).

9 Para 2004, os decis equivalem (em valores de 2006) a: 1ㅇ decil - R\$ 83,16; 2o decil - $\mathrm{R} \$ 129,61 ; 3^{\circ}$ decil - $\mathrm{R} \$ 177,13$;

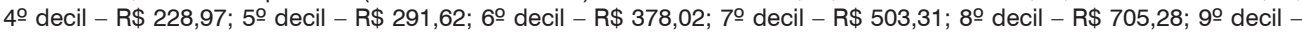
$\mathrm{R} \$ 1.188,07 ; 10$ o decil - R\$ 66.153,86. Para 2006, equivalem a: 1 o decil - R\$ 106,00; 2ㅇ decil - R\$ 160,00; 3 o decil -

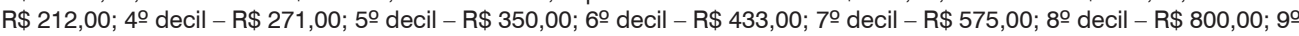
decil - R\$1.350,00; 10 decil - $R \$ 46.266,00$. O salário mínimo em 2006 correspondia a $R \$ 350,00$.

10 Resultados de outras pesquisas também evidenciam o pequeno acesso dos domicílios metropolitanos a programas governamentais de transferência de renda. A Pesquisa de Condições de Vida - PCV 2006, da Fundação Seade, mostra para a Região Metropolitana de São Paulo, em 2006, que 9\% das famílias tinham acesso a benefícios oriundos dos programas governamentais de transferência de renda. Disponível em: <http://www.seade.gov.br>. Acesso em: 28/03/2008.
} 
no acesso dos domicílios caracterizados anteriormente como arranjos mais vulneráveis ao empobrecimento.

Considerando o conjunto dos domicílios metropolitanos segundo decis de renda familiar per capita, foram encontradas semelhanças em 2004 e 2006 nas proporções daqueles com acesso a programas governamentais de transferência de renda entre os decis inferiores de renda familiar per capita. Tinham acesso a algum tipo desses programas cerca de $27 \%$ dos $10 \%$ de domicílios mais pobres, em torno de $53 \%$ dos $20 \%$ mais pobres e cerca de $91 \%$ dos $50 \%$ mais pobres (Tabela 4). Acima do 50 decil, apenas $9 \%$ dos domicílios tinham acesso

TABELA 4

Distribuição dos domicílios que possuem transferência de renda, por decis do rendimento domiciliar per capita, segundo tipos de arranjo domiciliar - estimativa (1) Regiões metropolitanas brasileiras - 2004-2006

\begin{tabular}{|c|c|c|c|c|c|c|}
\hline \multirow{3}{*}{ Tipos de arranjo domiciliar } & \multicolumn{3}{|c|}{$\%$ Linha } & \multicolumn{3}{|c|}{$\%$ Coluna } \\
\hline & \multicolumn{3}{|c|}{ Decis inferiores da renda } & \multicolumn{3}{|c|}{ Decis inferiores da renda } \\
\hline & $10 \%$ & $20 \%$ & $50 \%$ & $10 \%$ & $20 \%$ & $50 \%$ \\
\hline \multicolumn{7}{|l|}{$2004(2)$} \\
\hline Casais & 25,7 & 52,0 & 90,7 & 66,3 & 68,5 & 69,8 \\
\hline Casal sem filhos & 13,6 & 25,1 & 76,0 & 1,3 & 1,2 & 2,1 \\
\hline Casal com filhos e parentes & 26,2 & 53,0 & 91,3 & 65,0 & 67,3 & 67,7 \\
\hline Casal até 34 anos com filhos e parentes & 28,8 & 60,2 & 93,8 & 27,5 & 29,4 & 26,8 \\
\hline Casal de 35 a 49 anos com filhos e parentes & 25,6 & 50,1 & 90,7 & 26,7 & 26,6 & 28,2 \\
\hline Casal de 50 anos e mais com filhos e parentes & 16,1 & 38,0 & 81,7 & 4,1 & 4,9 & 6,2 \\
\hline Chefe feminina sem cônjuge & 31,2 & 56,8 & 92,1 & 31,7 & 29,4 & 27,9 \\
\hline Chefe feminina sem cônjuge - e/ou filhos e/ou parentes & 32,1 & 58,2 & 92,7 & 31,7 & 29,3 & 27,3 \\
\hline Chefe feminina unipessoal & . & 6,6 & 70,9 & . & 0,1 & 0,6 \\
\hline Chefe masculino sem cônjuge & 20,4 & 40,9 & 76,9 & 2,1 & 2,1 & 2,3 \\
\hline Chefe masculino sem cônjuge - e/ou filhos e/ou parentes & 26,2 & 52,6 & 83,2 & 2,1 & 2,1 & 2,0 \\
\hline Chefe masculino unipessoal & . & . & 54,8 & . & . & 0,4 \\
\hline Total (3) & 27,1 & 53,0 & 90,7 & 100,0 & 100,0 & 100,0 \\
\hline \multicolumn{7}{|l|}{2006} \\
\hline Casais & 26,5 & 51,5 & 91,5 & 64,3 & 66,3 & 67,0 \\
\hline Casal sem filhos & 7,8 & 16,4 & 68,1 & 1,0 & 1,1 & 2,6 \\
\hline Casal com filhos e parentes & 27,5 & 53,5 & 92,8 & 63,3 & 65,2 & 64,5 \\
\hline Casal até 34 anos com filhos e parentes & 30,8 & 59,4 & 94,9 & 28,5 & 29,1 & 26,4 \\
\hline Casal de 35 a 49 anos com filhos e parentes & 26,3 & 52,9 & 92,7 & 24,1 & 25,7 & 25,7 \\
\hline Casal de 50 anos e mais com filhos e parentes & 13,9 & 31,8 & 82,3 & 3,5 & 4,3 & 6,3 \\
\hline Chefe feminina sem cônjuge & 31,2 & 54,8 & 92,6 & 34,1 & 31,8 & 30,5 \\
\hline Chefe feminina sem cônjuge - e/ou filhos e/ou parentes & 32,1 & 56,8 & 93,8 & 33,6 & 31,4 & 29,5 \\
\hline Chefe feminina unipessoal & 11,2 & 13,9 & 66,5 & 0,6 & 0,4 & 1,0 \\
\hline Chefe masculino sem cônjuge & 15,6 & 36,4 & 80,3 & 1,6 & 1,9 & 2,4 \\
\hline $\begin{array}{l}\text { Chefe masculino sem cônjuge - e/ou filhos e/ou paren- } \\
\text { tes }\end{array}$ & 18,0 & 42,9 & 82,9 & 1,5 & 1,9 & 2,1 \\
\hline Chefe masculino unipessoal & 3,1 & 3,1 & 66,9 & 0,1 & 0,0 & 0,3 \\
\hline Total (3) & 27,6 & 52,1 & 91,5 & 100,0 & 100,0 & 100,0 \\
\hline
\end{tabular}

Fonte: IBGE. Pesquisa Nacional por Amostra de Domicílios 2004 e 2006. Elaboração dos autores, Nepp/Unicamp.

(1) Estimativa obtida através da variável V1273.

(2) Em valores de 2006 (INPC).

(3) Inclui outros tipos de arranjos domiciliares (residual). 
a tais programas e estão situados nos 6을 $7^{\circ}$ e e $8^{\circ}$ decis, indicando a focalização nos estratos de renda mais baixos.

Um detalhamento da análise evidencia a manutenção, em 2004 e 2006, das maiores concentrações de domicílios beneficiários entre aqueles identificados como mais vulneráveis ao empobrecimento. Para os $10 \%$ mais pobres com acesso a programas de transferência de renda, em 2006, pouco mais que um quarto correspondia a casais jovens com filhos, um quarto era de casais na etapa de consolidação da família e um terço compunha-se de famílias chefiadas por mulher sem a presença de cônjuge.

Entre os arranjos domiciliares que evidenciam maiores fragilidades, destacam-se aqueles caracterizados pelos casais de até 34 anos, com filhos e parentes, que também apresentavam as maiores proporções (cerca de $94 \%$, em 2004, e $95 \%$, em 2006) com acesso a algum programa de transferência de renda nos estratos abaixo do 5 o decil de renda domiciliar per capita metropolitana - correspondentes aos $50 \%$ mais pobres. Cerca de $59 \%$ dos domicílios deste tipo, com acesso, encontravam-se abaixo do $2^{\circ}$ decil, ou seja, entre os $20 \%$ mais pobres (Tabela 4).

O segundo grupo com maior acesso entre os $50 \%$ mais pobres corresponde aos domicílios chefiados por mulher sem cônjuge e com presença de filhos e/ou parentes, exatamente o segundo arranjo domiciliar identificado por esse estudo como um dos mais vulneráveis ao empobrecimento, entre os quais cerca de $94 \%$ tinham acesso a renda de transferência governamental, em 2006 (Tabela 4).

O terceiro grupo com maior acesso entre os 50\% mais pobres é composto por domicílios nucleados pelo casal com idades entre 35 e 49 anos com a presença de filhos e/ou parentes, da ordem de 93\% em 2006 (Tabela 4).

Considerando-se o conjunto dos tipos de arranjos domiciliares, fica evidente a focalização nos três tipos apontados como mais vulneráveis ao empobrecimento em ambos os períodos - casal de até 34 anos com filhos e parentes, casal entre 34 e 49 anos com filhos e parentes e chefe feminina sem cônjuge com filhos e parentes -, que juntos perfazem mais de $80 \%$ dos domicílios com acesso a algum programa de transferência de renda, tanto se considerados os $10 \%$ mais pobres ou os $20 \%$ mais pobres, como os $50 \%$ mais pobres (Tabela 4 ).

$\mathrm{O}$ acesso aos programas governamentais de transferência de renda pelos domicílios caracterizados por arranjos mais vulneráveis ao empobrecimento indica, ao mesmo tempo, a confirmação dessa vulnerabilidade ao empobrecimento, como a focalização dos programas nos domicílios mais pobres.

A análise do impacto dos valores transferidos por tais programas sociais sobre 0 rendimento familiar per capita dos domićlios com acesso explicita dois aspectos. $\mathrm{O}$ primeiro refere-se ao maior peso das transferências para os domicílios situados no primeiro decil de renda familiar per capita e à redução gradual do mesmo a partir do segundo decil (Tabela 5). No caso dos domicílios de casais de até 34 anos com filhos e de casais de 35 a 49 anos com a presença de filhos, os percentuais de transferências sobre a renda per capita domiciliar são mais relevantes para aqueles situados nos três decis inferiores de renda. No caso dos domicílios das chefes femininas sem a presença de cônjuge e com filhos e/ou parentes, embora com menor intensidade que no primeiro decil, a proporção das transferências sobre a renda per capita é relevante em praticamente todos os decis de renda.

O segundo aspecto refere-se ao fato de que as proporções da renda oriunda das transferências monetárias são mais importantes no primeiro e no quinto decis de renda dos domicílios com acesso. Merece ressalvar o peso do valor das transferências de renda para os domicílios unipessoais femininos e masculinos no primeiro e no quinto decis. O programa Bolsa-Família ampliou o benefício para famílias pobres sem filhos e possivelmente foi incorporado um maior número de domicílios em situação de indigência, aumentando o impacto das transferências nos domicílios unipessoais femininos e masculinos no primeiro decil de renda familiar per capita, com importante 


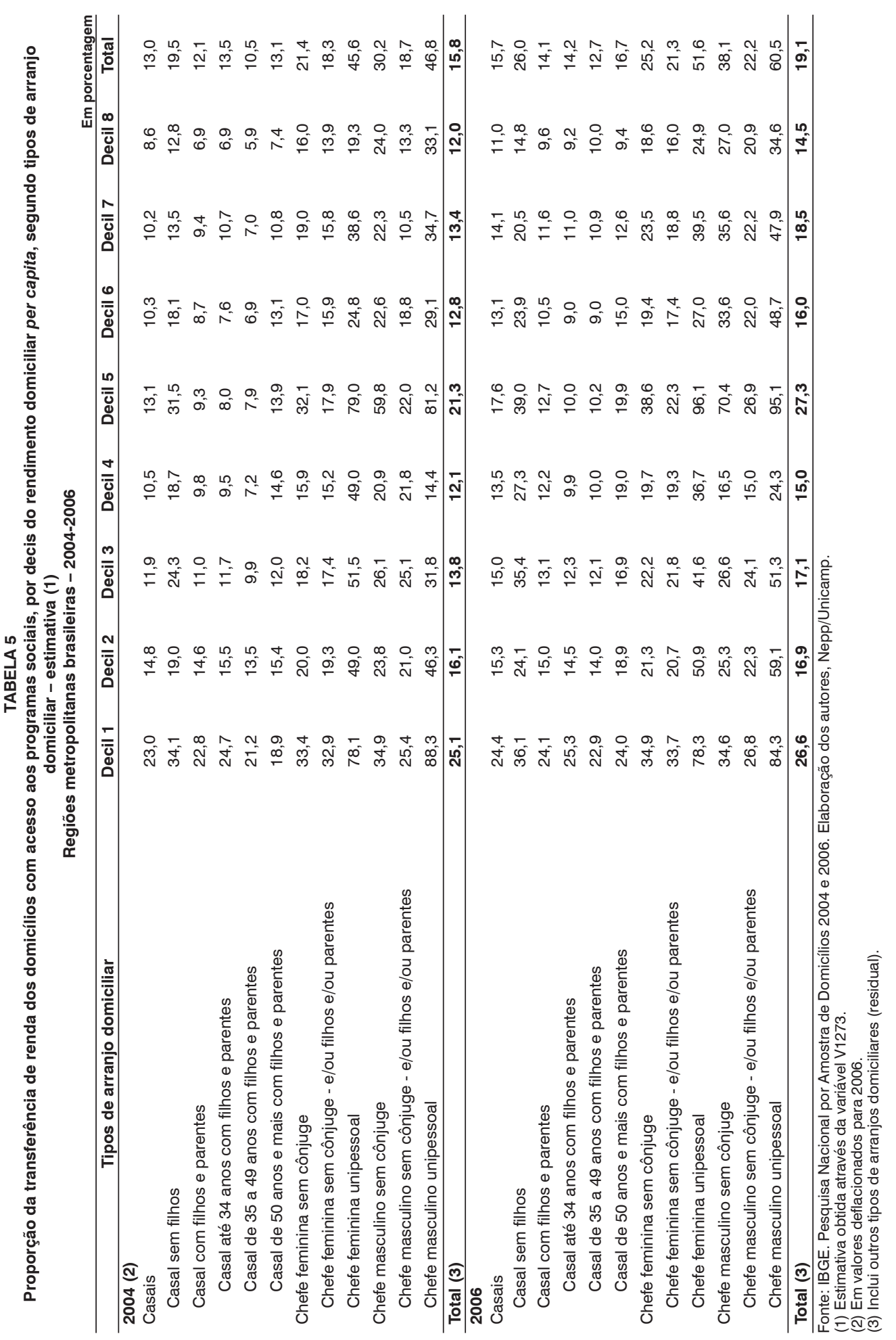


peso na renda domiciliar (Tabela 5). A concentração no quinto decil indica o acesso desses domicílios ao Benefício de Prestação Continuada (BPC), cujo valor é um salário mínimo. O corte de renda do quinto decil é bastante próximo do valor do salário mínimo em 2004 e 2006, conforme observado na nota 10 deste texto.

É interessante observar como o acesso a programas de transferência está relacionado à composição dos domicílios e aos distintos arranjos domiciliares associados a ciclos vitais da família (Tabela 6). Observa-se que o Beneficio de Prestação Continuada, que atende deficientes e principalmente idosos em situação de risco, apresenta peso maior entre as famílias unipessoais (caracterizadas por idosos), entre os arranjos nucleados pelos casais de 50 anos com filhos e/ou parentes, bem como para os casais sem filhos residentes, entre os quais uma parcela importante é composta por idosos. Representa ainda cerca de 15\% dos benefícios a que têm acesso os domicílios com chefia feminina sem a presença de cônjuge, lembrando-se que, nestes, 55\% das chefes têm 50 anos ou mais. Nos demais arranjos familiares é pouco expressiva sua participação (Tabela 6).

Por sua vez, o programa Bolsa-Família apresenta peso importante entre os programas de transferência de renda, abrangendo cerca de $74 \%$ dos domicílios metropolitanos com acesso. É mais elevado o acesso ao Bolsa-Família pelos três tipos de arranjos identificados como mais vulneráveis ao empobrecimento, que contam em sua composição familiar com parcela importante de crianças, adolescentes e jovens, ou seja, os tipos de arranjo domiciliar: casal de até 34 anos com filhos e/ou parentes; casal entre 34 e 49 anos com filhos e/ou parentes; e chefe feminina sem cônjuge, com filhos e parentes. Entre estes, observa-se também maior acesso ao PETI (Programa de Erradicação do Trabalho Infantil) (Tabela 6).

Para finalizar estas considerações acerca dos programas de transferência de renda e sobre a situação social, cabe retomar a questão dos efeitos destes sobre a redução dos domicílios com renda zero. Outro aspecto a se considerar é se houve aumento da proporção de domicílios com

TABELA 6

Distribuição dos domicílios com acesso a programas de transferência de renda, por tipo de programa, segundo tipos de arranjo domiciliar

Regiões metropolitanas brasileiras - 2006

Em porcentagem

\begin{tabular}{|c|c|c|c|c|c|}
\hline Tipos de arranjo domiciliar & $\begin{array}{l}\text { Bolsa- } \\
\text { Família }\end{array}$ & $\begin{array}{l}\text { BPC- } \\
\text { LOAS }\end{array}$ & PETI & $\begin{array}{c}\text { Outro programa } \\
\text { (1) }\end{array}$ & Total \\
\hline Casais & 76,2 & 8,9 & 1,1 & 13,7 & 100,0 \\
\hline Casal sem filhos & 49,9 & 35,2 & 1,1 & 13,8 & 100,0 \\
\hline Casal com filhos e parentes & 77,6 & 7,5 & 1,1 & 13,7 & 100,0 \\
\hline Casal até 34 anos com filhos e parentes & 82,9 & 3,4 & 1,1 & 12,7 & 100,0 \\
\hline Casal de 35 a 49 anos com filhos e parentes & 79,1 & 5,0 & 1,2 & 14,8 & 100,0 \\
\hline Casal de 50 anos e mais com filhos e parentes & 55,8 & 30,1 & 0,7 & 13,4 & 100,0 \\
\hline Chefe feminina sem cônjuge & 70,6 & 15,4 & 0,8 & 13,2 & 100,0 \\
\hline Chefe feminina sem cônjuge - e/ou filhos e/ou parentes & 72,4 & 13,2 & 0,8 & 13,6 & 100,0 \\
\hline Chefe feminina unipessoal & 32,4 & 62,7 & 0,0 & 4,9 & 100,0 \\
\hline Chefe masculino sem cônjuge & 41,6 & 39,8 & 0,0 & 18,6 & 100,0 \\
\hline Chefe masculino sem cônjuge - e/ou filhos e/ou parentes & 48,0 & 31,7 & 0,0 & 20,3 & 100,0 \\
\hline Chefe masculino unipessoal & 6,1 & 84,7 & 0,0 & 9,1 & 100,0 \\
\hline Total (2) & 73,6 & 11,7 & 1,0 & 13,7 & 100,0 \\
\hline
\end{tabular}

Fonte: IBGE. Pesquisa Nacional por Amostra de Domicílios 2006. Elaboração dos autores

(1) Federal, estadual ou municipal.

(1) Inclui outros tipos de arranjo domiciliar (residual). 


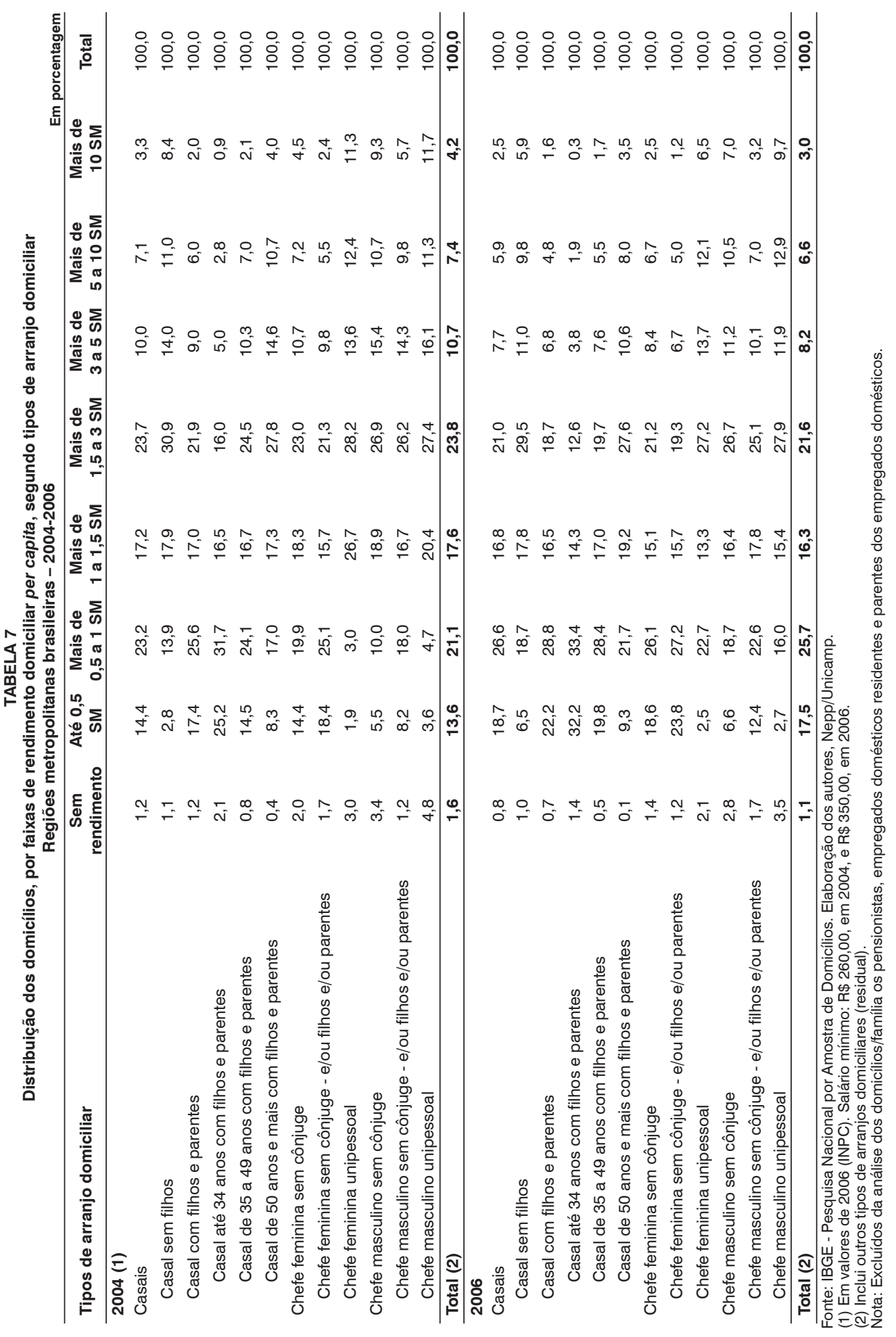


rendimento per capita nas faixas até três salários mínimos (Tabela 7).

Constatou-se que houve pequena redução de domicílios com renda zero nesse período. Embora pequena em pontos percentuais para a média dos domicílios metropolitanos ( 0,5 ponto percentual), essa diminuição foi mais expressiva naqueles mais vulneráveis ao empobrecimento e nos domicílios unipessoais femininos e masculinos (Tabela 7).

Considerando-se os arranjos mais suscetíveis ao empobrecimento, suas características de composição domiciliar e fase do ciclo de vida familiar, verifica-se, entre 2004 e 2006, redução na proporção dos domicílios sem rendimento entre os arranjos casal de até 34 anos com filhos e parentes $(0,7$ ponto percentual), casal entre 34 e 49 anos com filhos e parentes ( 0,3 ponto percentual) e chefe feminina sem cônjuge, com filhos e parentes $(0,5$ ponto percentual). Como especificidades, observa-se crescimento nas proporções dos domicílios com rendimento per capita nas categorias até meio e um salário mínimo. Na faixa entre um e um e meio salário mínimo, com a exceção dos domicílios nucleados pela chefe feminina sem cônjuge, que se mantiveram em 15,7\%, não houve aumento na proporção daqueles com maior indicação de vulnerabilidade ao empobrecimento; pelo contrário, reduziramse aqueles compostos pelo casal de até 34 anos, com filhos e/ou parentes. Nestes casos em que os domicílios apresentam rendimentos mais baixos, ao que parece, as transferências de renda e as condições do mercado de trabalho favorecem menores possibilidades de superação de condições precárias.

A redução da proporção de domicílios com renda zero, nas regiões metropolitanas brasileiras, pode ser tomada como uma evidência de impactos de programas de transferência de renda. Observou-se tal redução com intensidade semelhante em todos os agrupamentos de áreas metropolitanas segundo as grandes regiões, com exceção daquelas da Região Sul, onde esse decréscimo apresentou menor intensidade. Evidencia-se variação positiva, entre 2004 e 2006, apenas para as faixas de rendimento domiciliar per capita entre meio e um salário mínimo, que apresentam, respectivamente, elevação em 4 e 4,6 pontos percentuais. Esses movimentos evidenciam redução da indigência, porém com pequeno impacto na diminuição da pobreza. Interpretação semelhante é sugerida também por outros pesquisadores (BARROS, et al., 2006).

$\mathrm{Na}$ presente análise comparativa dos dados da PNAD 2004 e 2006, esta interpretação de redução da indigência com pequeno impacto na queda da pobreza é respaldada pelo contexto de precarização do trabalho e de permanência de elevado desemprego metropolitano no período analisado - apesar da tendência de arrefecimento -, além do crescimento da economia pouco intenso até 2006. Ainda que tenha ocorrido, nesse período, elevação do emprego e do emprego regulamentado, é pequena a recuperação da renda dos ocupados, como evidenciado na primeira parte do artigo, e muito pequena a elevação da renda familiar per capita nas regiões metropolitanas.

\section{Considerações finais}

A presente análise indica, por um lado, a focalização dos programas de transferência de renda nos domicílios mais pobres e nos grupos de domicílios que, por vivenciarem momentos distintos do ciclo vital familiar, abrigam crianças e adolescentes ou idosos, muitas vezes apresentando condições menos favoráveis para articular a sobrevivência.

Por outro lado, constatou-se redução nos domicílios com rendimento zero em todos os agrupamentos de regiões metropolitanas analisados, que, embora pequena, foi mais expressiva nos domicílios identificados como mais suscetíveis ao empobrecimento, bem como em domicílios unipessoais femininos e masculinos.

A redução da proporção de domicílios com renda zero, nas regiões metropolitanas brasileiras, é assumida por nós como uma evidência de impactos de programas de transferência de renda. Já a concomitante variação positiva entre 2004 e 2006 apenas para as faixas de rendimento domiciliar per capita entre meio e um salário mínimo é 
interpretada como indício de redução da indigência, porém com pequeno impacto na diminuição da pobreza.

A hipótese de que o acesso aos programas de transferência de renda e o contexto de retomada do emprego poderiam promover redução da desigualdade de rendimentos para os grupos de domicílios identificados neste estudo como mais vulneráveis ao empobrecimento não se confirma. Um dos indícios é de movimento inverso, pois se, por um lado, houve pequena elevação no rendimento familiar per capita nas regiões metropolitanas brasileiras no período analisado, por outro, essa elevação é distinta entre os tipos de arranjos domiciliares e ocorreu de forma desfavorável em relação aos três tipos de família identificados como mais vulneráveis ao empobrecimento, reproduzindo a desigualdade de renda entre os domicílios.

A taxa de geração de renda comparativamente menos elevada dos arranjos domiciliares identificados como mais vulneráveis ao empobrecimento apresentou, no período analisado, crescimento menor do que a média dos domicílios metropolitanos. No caso dos domicílios com chefia feminina sem a presença de cônjuge, embora se verifique redução da taxa de desemprego, soma-se a proporção mais elevada que a média de ocupações precárias, indicando para esse conjunto de arranjos domiciliares as condições mais desfavoráveis para inserção no mercado.

Dessa maneira, entre os arranjos mais suscetíveis ao empobrecimento, tendo presentes as características de composição domiciliar e fase do ciclo de vida familiar - casal de até 34 anos com filhos e parentes, casal entre 34 e 49 anos com filhos e parentes

\section{Referências bibliográficas}

ARRIAGADA, I. Estruturas familiares, trabalho e bem-estar na América Latina. In: ARAUJO, C.; PICANÇO, F.; SCALON, C. (Orgs.). Novas conciliações e antigas tensões? Gênero, família e trabalho em perspectiva comparada. Bauru: Edusc, 2007.

BARROS, R. P.; FOGUEL, M. N.; ULYSSEA, G. (Orgs.). Desigualdade de renda no e chefe feminina sem cônjuge, com filhos e parentes -, são evidentes a redução na proporção dos domicílios sem rendimento e o crescimento daqueles com rendimento per capita nas categorias até meio e um salário mínimo. Na faixa superior não se observou aumento na proporção destes domicílios. Ao que parece, nestes casos em que os domicílios apresentam rendimentos mais baixos, as transferências de renda e as condições do mercado de trabalho não favorecem possibilidades de superação da condição de pobreza.

Há indícios de que os programas sociais vêm afetando positivamente as famílias nos estratos mais baixos de rendimento familiar per capita, reduzindo a condição de indigência. No entanto, em 2004 e 2006, permaneceu pequena a atuação destes programas de transferência de renda nas regiões metropolitanas brasileiras, onde está concentrada grande parte da população classificada como pobre pelos estudiosos do tema.

Em decorrência desse fato e da concentração de importante parcela da população brasileira nestas regiões, há necessidade de investimentos maciços nas regiões metropolitanas brasileiras para promover alguma mitigação da pobreza nesses espaços. Essa observação é feita explicitando-se que, além da necessidade da elevação do montante do benefício para atender aos custos mais elevados da vida metropolitana, é fundamental a implementação de programas complementares de geração de renda, de capacitação dos jovens para o mercado de trabalho e de iniciativas para a redução de desigualdades de gênero e raça no acesso ao trabalho e nos rendimentos auferidos pelo trabalho.

Brasil: uma análise da queda recente. Brasília: Ipea, 2006.

BERQUÓ, E. Arranjos familiares no Brasil: uma visão demográfica. In: SCHWARCZ, L. M. (Org.). História da vida privada no Brasil. São Paulo: Cia das Letras, vol. 4, 2000. 
CEPAL - Comisión Económica para América Latina. La protección social: de cara para al futuro - acceso, financiamiento y solidariedad. Montevideo, Uruguay: Cepal, 20 a 24 de março 2006.

DEDECCA, C. S. A redução da desigualdade no Brasil: uma estratégia complexa. In: BARROS, R. P; FOGUEL, M. N.; ULYSSEA, G. (Orgs.). Desigualdade de renda no Brasil: uma análise da queda recente. Brasília: Ipea, 2006.

. O trabalho da mulher e sua contribuição para a renda da família. Programa Trabalho e Gênero no Brasil: formas, tempo e contribuição sócioeconômica. Unifem, 2005.

DRAIBE, S. Por um reforço da proteção à família: contribuição à reforma dos programas de assistência social no Brasil. In: KALOUSTIAN, S. M. (Org.). Família brasileira a base de tudo. Brasília: Unicef, Cortez Editora, 1994.

Brasil: Bolsa-Escola y BolsaFamilia. Série Cadernos de Pesquisas - Nepp, Campinas, Nepp/Unicamp, n. 76, 2006.

. RIESCO, M. Estado de bienestar, desarrollo económico y ciudadanía: algunas lecciones de la literatura contemporánea. Serie Estudios y Perspectivas, México, DF: Cepal, n. 55, ago. 2006.

FUNDAÇÃO SEADE; DIEESE. PED: o mercado de trabalho metropolitano 19982005. Disponível em: <http://www.seade. gov.br> 2007.

PED - Regióes Metropolitanas. Disponível em: <http://www.seade.gov.br>. Acesso em: 02/04/2008.

Resultados da Pesquisa de Condições de Vida - PCV 2006. Disponível em: <http://www.seade.gov.br>. Acesso em: 28 mar. 2008.

FONSECA, A. M. M. Família e política de renda mínima. São Paulo: Cortez Editora, 2001.

FONSECA, A. M. M.; COHN, A. O BolsaFamília e a questão social. In: SEGUNDO
WORKSHOP INTERNACIONAL SOBRE TRANSFERÊNCIA CONDICIONAL DE RENDA. Ministério do Desenvolvimento Social e Combate à Fome. São Paulo, Brasil, abr. 2004.

HOFFMANN, M.; MENDONÇA, S. O mercado de trabalho na região metropolitana de São Paulo. Estudos Avançados, São Paulo, USP, v. 17, n. 47, p. 21-42, 2003.

IBGE-MDS. Acesso a transferências de renda de programas sociais - Pesquisa Nacional por Amostra de Domicílios 2006. Rio de Janeiro, IBGE, 2008.

IPEA. Boletim de Politicas Sociais, Brasília, n.13. Edição Especial 2007.

Pobreza e riqueza no Brasil metropolitano. Comunicado da Presidência, Brasília, n. 7, agosto de 2008.

JANNUZZI, P. de M. Evolução da renda e pobreza na Grande São Paulo nos anos 90: evidências empíricas e outros subsídios para a formulação de políticas de combate à indigência. Pesquisa \& Debate, São Paulo, 12(2), 14-43, 2000

JELIN, E. Las familias latinoamericanas en el marco de las transformaciones globales: hacia una nueva agenda de políticas públicas. In: REUNIÓN DE EXPERTOS: POLÍTICAS HACIA LAS FAMILIAS, PROTECCIÓN E INCLUSIÓN SOCIALES. Buenos Aires, Cepal, Conicet - Facultad de Ciencias Sociales Universidad de Buenos Aires, 28 y 29 de jun. 2005.

LANGEVIN, A. La famile en recherche. Configurations familiales et vie domestique, v. 30, p. 205-232, 2001 (Cahiers du Genre).

LEONE, E. T. Trabalho da mulher em regiões metropolitanas do Brasil. In: PRONI, M. W.; WILNÊS, H. (Orgs.). Trabalho, mercado e sociedade: o Brasil nos anos 90. São Paulo: Editora Unesp; Campinas: Instituto de Economia da Unicamp, 2003.

LEONE, E. T.; HOFFMANN, R. Participação da mulher no mercado de trabalho e desigualdade de renda domiciliar per capita no Brasil: 1981-2002. Nova Economia, 
Revista do Departamento de Ciências Econômicas da UFMG, v. 14, n. 2, 2004.

MONTALI, L. Família e trabalho na reestruturação produtiva: ausência de políticas de emprego e deterioração nas condições de vida. Revista Brasileira de Ciências Sociais, Anpocs, n.42, fev. 2000.

. Relação família-trabalho: reestruturação produtiva e desemprego. Revista São Paulo em Perspectiva, São Paulo, Fundação Seade, v. 17, abril-junho 2003.

. Rearranjos familiares de inserção,

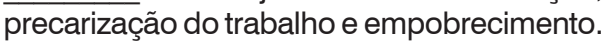
Revista Brasileira de Estudos de População, Abep, v. 21, n. 2, jul./dez. 2004a.

Precarização do trabalho, desemprego e os rearranjos de inserção familiares - 1985 a 2000. Campinas: Nepp/ Unicamp, jun. 2004b (Relatório de Pesquisa CNPq).

Provedoras e co-provedoras: muIheres-cônjuge e mulheres-chefe de família sob a precarização do trabalho e desemprego. Revista Brasileira de Estudos de População, Abep, v. 23, n. 2, jul./dez. 2006.

. Regiões metropolitanas: mudanças na família e na relação família-trabalho, as condições sociais e as políticas de transferência de renda. Campinas: Nepp/Unicamp, abril 2008 (Relatório de Pesquisa CNPq).

MONTALI, L.; TAVARES, M. Famílias metropolitanas: precarização do trabalho e empobrecimento. In: SEMINÁRIO POPULAÇÃO, POBREZA E DESIGUALDADE. Belo Horizonte-MG , 05-06 de novembro de 2007.
OLIVEIRA, Z. L. C. de. A provisão da família e a pobreza: o caso de Belo Horizonte. In: SEMINÁRIO AS FAMÍLIAS E AS POLÍTICAS PÚBLICAS NO BRASIL. Belo Horizonte, 2122 de novembro de 2005.

POCHMANN, M. A metrópole do trabalho. São Paulo, Brasiliense, 2001.

O desafio da inclusão. São Paulo: Publisher Brasil, 2004.

ROCHA, S. Pobreza no Brasil: afinal, de que se trata? Rio de Janeiro: Editora FGV, 2003.

Alguns aspectos relativos à evolução 2003-2004 da pobreza e da indigência no Brasil. Rio de Janeiro: Instituto de Estudos do Trabalho e Sociedade, jan. 2006. Disponível em: <http://www.iets.org.br/biblioteca/Transferencias_de_renda_focalizadas.pdf $>$.

SCHWARTZMAN, S. Redução da desigualdade, da pobreza, e os programas de transferência de renda. Instituto de Estudos do Trabalho e Sociedade, versão 3, 13 de fev. 2006.

SOARES, F. V.; SOARES, S.; MEDEIROS, M.; OSÓRIO, R. G. Programas de transferência de renda no Brasil: impactos sobre a desigualdade. Brasília: Ipea, 2006 (Texto para discussão, n. 1.228).

SOARES, P. Pobreza cai ao menor nível desde 1987. Folha de S. Paulo, Caderno Dinheiro, 19 de setembro de 2007. Disponível em: <http://www1.folha.uol.com.br/fsp/ dinheiro/fi1909200732.htm>. Acesso em: 15 out. 2007.

\section{Resumen}

Familia, pobreza y acceso a programas de transferencia de renta en las regiones metropolitanas brasileñas

El objetivo del artículo es evidenciar en las regiones metropolitanas brasileñas los asentamientos familiares más vulnerables al empobrecimiento e investigar el acceso de éstos a los programas de transferencia de renta, así como algunos efectos de estos programas sobre los ingresos de las familias. Los asentamientos domiciliarios más vulnerables al empobrecimiento son así identificados por poseer los más bajos ingresos familiares per cápita y concentración en las camadas inferiores de renta. Presentan estructuración y composiciones distintas, así como 
experimentan diferentes momentos del ciclo de vida familiar, pero son los más frágiles ante el cambio en el padrón de empleo, por presentar una composición familiar desfavorable para la inserción de sus componentes en el mercado de trabajo. En las regiones metropolitanas brasileñas, el empobrecimiento de los hogares ocurrido en los años 90 e inicios de los 2000 refleja la caída de los ingresos del trabajo proveniente de la precarización del mercado, bajo la reestructuración productiva y el bajo crecimiento económico hasta 2004. Hasta 2006, bajo la recuperación económica, tales ingresos no volvieron a los niveles de la mitad de los años 90. Entre las políticas de lucha contra la pobreza emergen aquéllas de transferencia de renta, que, al inicio de los años 2000, presentaban un alcance incipiente. Se intensifican en el transcurso de la década, posibilitando el aumento del acceso de los hogares con ingresos más bajos. En un análisis comparativo entre los datos de la PNAD 2004 y 2006, se procura identificar el acceso a los programas de transferencia de renta por los hogares caracterizados por diferentes tipos de asentamientos familiares, considerando su estructuración y momento del ciclo de vida familiar. Uno de los impactos a ser investigados dentro de éstos es la reducción de los hogares sin ingresos. Se investiga también la disminución de la desigualdad de ingresos entre los asentamientos familiares más vulnerables y los demás tipos, aunque aún permanezcan las diferencias del ingreso per cápita.

Palabras-clave: Familia-trabajo. Empobrecimiento. Programas de transferencia de renta.

\section{Abstract}

Family, poverty and access to income transfer programs in the metropolitan regions of Brazil

The objective of this article is to describe the family arrangements most vulnerable to impoverishment in the metropolitan regions of Brazil and to investigate the access of very poor families to such programs, as well as some of their effects on the earnings of these families. The household arrangements most vulnerable to impoverishment are those with the lowest per capita family income and those in the lowest income deciles. They show varying family structures and compositions and go through different moments in their family life cycles, but they are the hardest hit in terms of changes in employment patterns, since their family compositions are unfavorable for their members to enter the labor market. The impoverishment of households in the Brazilian metropolitan regions during the 1990s and the first years of the 21st century reflects the fall in income from work, due to the unstable job market that resulted from the restructuring of production and the country's low economic growth until 2004. Even by 2006, with economic improvements, these earnings failed to return to the levels of the mid-1990s. Among the policies set up in the government's "fight against poverty," one resource was the income transfer program, which was quite limited in the first years of the new century. It was intensified during the decade, enabling easier access to low-income households. By presenting a comparative analysis between the data from the PNADs of 2004 and 2006, we seek in this article to identify the access to such programs by households characterized by different types of family arrangements, considering their structures and the stage in the families' life cycle. One of the impacts to be investigated is the fall in the number of households with zero income. The lower inequality in income among the most vulnerable family arrangements, as well as among other types, are also discussed, and it is noted that there continue to be differences in per capita income.

Keywords: Family work. Impoverishment. Income transfer programs.

Recebido para publicação em 07/08/2008. Aceito para publicação em 14/11/2008. 